\title{
Factors Influencing Quality of Life during the First Trimester of Pregnancy: A Prospective Cohort Study
}

\author{
Lina Jakubauskiene ${ }^{1,2} \oplus$, Matas Jakubauskas ${ }^{1,3}\left(\mathbb{0}\right.$, Antanas Mainelis ${ }^{1,4}$, Diana Buzinskiene ${ }^{1,2}$, \\ Grazina Drasutiene ${ }^{1,2}$, Diana Ramasauskaite ${ }^{1,2} \mathbb{D}$ and Tomas Poskus 1,3,*(D) \\ 1 Faculty of Medicine, Vilnius University, 03101 Vilnius, Lithuania; morozovaite.lina@gmail.com (L.J.); \\ matasjakub@gmail.com (M.J.); antanas.mainelis@santa.lt (A.M.); diana.buzinskiene@santa.lt (D.B.); \\ grazina.drasutiene@santa.lt (G.D.); diana.ramasauskaite@santa.lt (D.R.) \\ 2 Clinic of Obstetrics and Gynecology, Vilnius University Hospital "Santaros Klinikos", \\ 08410 Vilnius, Lithuania \\ 3 Center of Abdominal Surgery, Vilnius University Hospital “Santaros Klinikos”, 08410 Vilnius, Lithuania \\ 4 Faculty of Mathematics and Informatics, Vilnius University, 03225 Vilnius, Lithuania, \\ * Correspondence: tomas.poskus@santa.lt; Tel.: +370-6867-8893
}

Received: 4 September 2019; Accepted: 23 September 2019; Published: 1 October 2019

\begin{abstract}
Introduction: Pregnancy, delivery and postpartum periods are associated with fast changes leading to decreased self-confidence, anxiety, stress or even maternal depression impairing their quality of life (QOL). Although considered important, QOL of women during pregnancy is poorly understood. The aim of our study was to assess factors influencing QOL during first trimester of pregnancy. The secondary goal of our study was to evaluate whether QOL during first trimester of pregnancy is associated with newborn weight. Materials and methods: A prospective cohort study was performed including pregnant women during the first trimester visit. Our questionnaire consisted of the SF-36 QOL questionnaire, Wexner fecal incontinence scale, and other additional information. The SF-36 questionnaire mental (MCS) and physical (PCS) health scores were used in order to evaluate QOL of women during first trimester of pregnancy. Two multiple logistic regression models were created in order to determine independent variables that influence the QOL. Results: 440 pregnant women were included in the study. The two main domains that were used in the study were MCS and PCS, their medians were $50.0(25.0 ; 50.0)$ and $50.1(39.4 ; 59.0)$ points respectively. From the two logistic regression models we determined several independent factors that influence QOL of women during the first trimester of pregnancy. Additionally, we determined that women who reported worse QOL tended to give birth to newborns large for their gestational age. Conclusions: We found several significant variables that influence QOL of women during the first trimester of pregnancy. We also found that that lower MCS and PCS scores during the first trimester are associated with newborns large for gestational age.
\end{abstract}

Keywords: quality of life; first trimester; pregnancy; prospective study; risk

\section{Introduction}

Pregnancy, delivery and postpartum periods are associated with fast hormonal, emotional and social changes, leading to decreased self-confidence, anxiety, stress or even maternal depression that can impact the health of both mothers and children [1-3].

Morbidity and mortality rates in obstetrics remain crucial for analyzing outcomes. However, improvement of maternal quality of life (QOL) during pregnancy is also very important from a population health standpoint. In recent years, QOL studies became a topic of interest in healthcare. QOL assessment is important for prevention and treatment programs [4]. Although considered 
important, QOL of women during pregnancy is poorly understood. Several studies investigating QOL of pregnant women focus only on specific illnesses, such as gestational diabetes mellitus, hypertension, and depression, and overlook daily socioeconomic factors that influence the QOL in the general population of pregnant women [5]. A recent review by Lagadec et al. shows that maternal QOL tend to decrease or remain stable throughout pregnancy [6]. With this in mind and the fact, that interventions to improve quality of life take time to provide results, interventions must start as early as possible-before conception or in the early periods of pregnancy $[7,8]$. The aim of our study was to assess factors influencing QOL during the first trimester of pregnancy. The secondary goal of our study was to evaluate whether QOL during the first trimester of pregnancy is associated with newborn weight.

\section{Materials and Methods}

We performed a prospective cohort study, which was approved by the Vilnius Regional Biomedical Research Ethics Committee (date of approval 2009-07-10, reference number: 158200-7-059-13). The study design is presented in detail in the publication by Poskus et al. [9].

\subsection{Study Population}

In this study we included pregnant women of 18-45 years of age, who gave birth in Vilnius University Hospital "Santaros Klinikos" between January 2010 and December 2011 and signed the consent form to participate. Women enrolled in this study were scheduled for a total of four visits (first trimester, third trimester, 1-2 days after delivery and a month after delivery). During all four visits the same gynaecologist (DB) interviewed and examined the women. Our period of interest for this publication is the primary visit during the first trimester of pregnancy when the participating women filled out a detailed questionnaire.

\subsection{Questionnaire}

Our questionnaire consisted of a SF-36 QOL questionnaire, Wexner fecal incontinence scale and other additional information, that can be classified into these groups: demographics, anthropometric data, dietary habits, use of oral supplements, use of alcohol and tobacco, exposure to tobacco fumes, physical activity, working conditions, living environment, obstetric history, perianal symptoms, defecation history and the presence of chronic health conditions.

\subsection{Statistical Analysis}

We used the SF-36 questionnaires mental (MCS) and physical (PCS) health scores to evaluate the women's QOL during the first trimester of pregnancy. In order to determine independent variables that influence the QOL we created two multiple logistic regression models (one for MCS and the other for PCS scores) using the stepwise method analyzing every possible variable from the questionnaire. A $p$-value of $<0.05$ was set for entry and removal of the variable from the model. Furthermore, using Kruskal-Wallis and Dunn's post hoc tests, we looked into the relationship between QOL and newborn weight groups (low birth weight $<10$ percentile; normal weight 10-90 percentile and large for gestational age $>90$ percentile) according to gestational age and sex (in this analysis we did not include women who were lost on follow-up). Statistical analyses were performed using SPSS ${ }^{\circledR}$ software version 21 (IBM, Armonk, NY, USA).

\section{Results}

A total of 440 pregnant women were included in the study. The mean age was $28.7 \pm 5.6$ years. Out of 440 women, 208 (47.3\%) were primiparous and 232 (52.7\%) were multiparous. Demographic and socio-economic results are presented in Table 1. 
Table 1. General demographic and clinical data.

\begin{tabular}{|c|c|}
\hline Characteristics & Study Group $(n=440)$ \\
\hline Patients' age (years) (mean \pm SD) & $28.7 \pm 5.6$ \\
\hline BMI before pregnancy $\left(\mathrm{kg} / \mathrm{m}^{2}\right)$ (median (range)) & $23.1(15.4-43.8)$ \\
\hline \multicolumn{2}{|l|}{ Gravidity $(n(\%))$} \\
\hline Nulligravida & $199(45.2 \%)$ \\
\hline Multigravida & $241(54.8 \%)$ \\
\hline \multicolumn{2}{|l|}{ Parity $(n(\%))$} \\
\hline Nulliparous & $208(47.3 \%)$ \\
\hline Multiparous & $232(52.7 \%)$ \\
\hline \multicolumn{2}{|l|}{ Marital status $(n(\%))$} \\
\hline Single & $107(24.3 \%)$ \\
\hline Married or partnership & $333(75.7 \%)$ \\
\hline \multicolumn{2}{|l|}{ Maternal education $(n(\%))$} \\
\hline High school & $60(13.6 \%)$ \\
\hline Incomplete university or college degree & $167(38.0 \%)$ \\
\hline University of college degree & $213(48.4 \%)$ \\
\hline \multicolumn{2}{|l|}{ Living area $(n(\%))$} \\
\hline Urban & $351(79.8 \%)$ \\
\hline Rural & $89(20.2 \%)$ \\
\hline \multicolumn{2}{|l|}{ Monthly household income $(n(\%))$} \\
\hline Less than average ( $<850$ euros) & $52(11.8 \%)$ \\
\hline Average (850 euros) & $326(74.1 \%)$ \\
\hline Above average (more than 850 euros) & $62(14.1 \%)$ \\
\hline
\end{tabular}

$\mathrm{SD}$, standard deviation.

Median values of all SF-36 questionnaire domains are presented in Table 2. The main two domains that further are used in the study are MCS and PCS, with their medians respectively 50.1 (IQR 39.4-59.0) and 48.2 (IQR 41.0-63.3) points.

Table 2. SF-36 questionnaire general results.

\begin{tabular}{cc}
\hline SF-36 Domains & Study Group $(\boldsymbol{n}=\mathbf{4 4 0})$ \\
\hline Physical function (median (IQR)) & $75.0(60.0-100.0)$ \\
Physical role function (median (IQR)) & $50.0(0.0-100.0)$ \\
Emotional role function (median (IQR)) & $66.7(0.0-100.0)$ \\
Vitality (median (IQR)) & $50.0(40.0-65.0)$ \\
Emotional well-being (median (IQR)) & $52.0(40.0-68.0)$ \\
Social functioning (median (IQR)) & $50.0(37.5-100.0)$ \\
Bodily pain (median (IQR)) & $55.0(45.0-100.0)$ \\
General health perceptions (median (IQR)) & $45.0(40.0-50.0)$ \\
Perceived change in health (median (IQR)) & $50.0(25.0-50.0)$ \\
Mental health score (MCS) (median (IQR)) & $50.1(39.4-59.0)$ \\
Physical health score (PCS) (median (IQR)) & $48.2(41.0-63.3)$ \\
\hline
\end{tabular}

IQR, Interquartile range.

Table 3 represents the PCS multiple logistic regression model. ANOVA p-value for the whole model is $<0.001$ and $R^{2}=0.804$.

MCS multiple logistic regression model is presented in Table 4. ANOVA p value for the whole model is $<0.001$ and $\mathrm{R}^{2}=0.779$. 
Table 3. Multiple logistic regression model for factors influencing physical (PCS) health scores.

\begin{tabular}{lll}
\hline Variable & Unstandardized Beta Coefficients & $p$-Value \\
\hline (Constant) & 78.404 & $<0.001$ \\
\hline Dietary & & 0.002 \\
Coffee consumption & -2.539 & 0.001 \\
How often fish and fish products are consumed weekly & -1.430 & 0.020 \\
How often meat and meat products are consumed weekly & 0.968 & 0.011 \\
How often fruits and vegetables are consumed weekly & -0.883 & 0.025 \\
How often milk and dairy products are consumed weekly & 0.922 & $<0.001$ \\
How often warm food is eaten during the day & -1.556 & $<0.001$ \\
Taste is the main criteria when choosing groceries & -2.179 & 0.001 \\
Snacking between meals & -4.994 & $<0.001$ \\
Use of oral nutritional supplements (except folic acid and iron supplements) & -2.662 & $<0.001$ \\
\hline Peri-anal symptoms & & $<0.001$ \\
Perianal pain during pregnancy & -7.600 & $<0.001$ \\
Defecation less than 3 times a week & -6.590 & 0.002 \\
Straining during defecation & 3.509 & \\
Pain during and after defecation & -2.732 & 0.016 \\
\hline Physical variables & & 0.006 \\
Current body weight & -0.060 & $<0.001$ \\
Rh(D) positive blood group & -2.106 & 0.001 \\
\hline Obstetric history & & $<0.001$ \\
History of perineal tear during delivery & -3.768 & $<0.001$ \\
Number of pregnancies & -1.978 & 0.002
\end{tabular}

Table 4. Multiple logistic regression model of factors influencing mental (MCS) health scores.

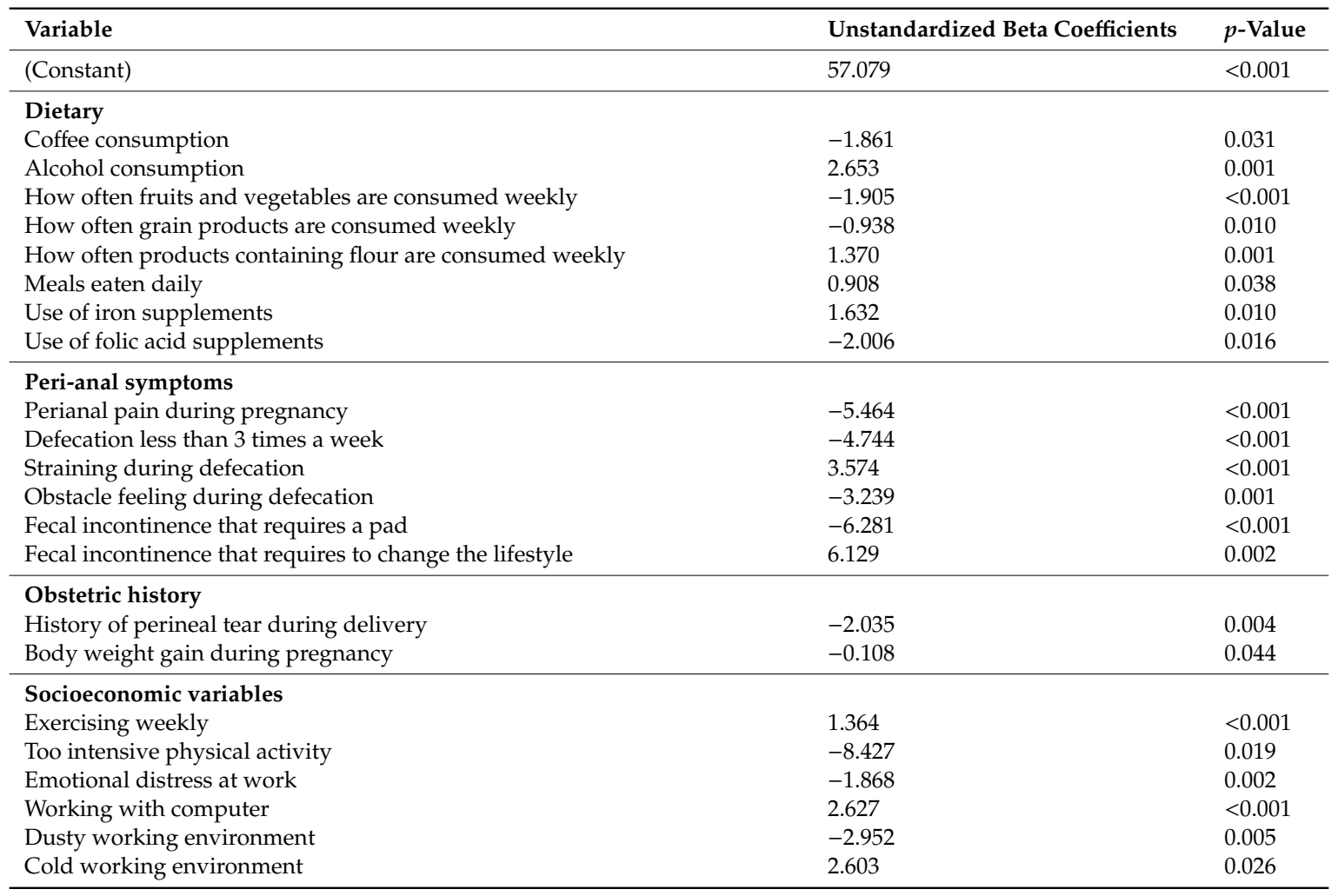


Additionally, we analyzed whether women's QOL during the first trimester of pregnancy is related to the weight of the newborn (Table 5). We did not include 160 women (36.4\%), who were lost to follow-up. We found that women who evaluated their QOL to be lower tended to give birth to newborns who were large for gestational age.

Table 5. Relationship between first trimester QOL and newborn weight.

\begin{tabular}{|c|c|c|c|c|c|c|}
\hline \multirow[b]{2}{*}{ QOL Variables } & \multicolumn{3}{|c|}{ Newborn Weight } & \multicolumn{3}{|c|}{$p$-Value } \\
\hline & $\begin{array}{c}\text { Low Birth } \\
\text { Weight } \\
\text { (<10 Percentile) } \\
(n=17)\end{array}$ & $\begin{array}{l}\text { Normal Weight } \\
\text { (10-90 Percentile) } \\
(n=226)\end{array}$ & $\begin{array}{c}\text { Large for } \\
\text { Gestational Age } \\
\text { (>90 Percentile) } \\
(n=37)\end{array}$ & $\begin{array}{l}\text { Low Birth Weight } \\
\text { vs. Normal } \\
\text { Weight }\end{array}$ & $\begin{array}{l}\text { Low Birth Weight } \\
\text { vs. Large for } \\
\text { Gestational Age }\end{array}$ & $\begin{array}{l}\text { Normal Weight } \\
\text { vs. Large for } \\
\text { Gestational Age }\end{array}$ \\
\hline $\begin{array}{l}\text { MCS (median } \\
\text { (IQR)) }\end{array}$ & $48.2(40.1-55.5)$ & $42.1(39.5-53.44)$ & $39.4(39.0-40.4)$ & 0.599 & $<0.001$ & $<0.001$ \\
\hline
\end{tabular}

\section{Discussion}

We analyzed maternal QOL during the first trimester of pregnancy in this study. Women in our study scored similarly in SF-36 subscale scores compared to the two other related studies [10,11]. We found several factors influencing reported QOL and we present them in two logistic regression models, one explaining the influence of factors on PCS and the other on MCS.

We determined that, among dietary factors, coffee consumption had a negative influence both for PCS and MCS. This could be partly explained by the fact that caffeine found in coffee acts as a stimulant and can cause symptoms similar to anxiety disorders (irritability, nervousness) [12]. Alcohol consumption tended to improve MCS of pregnant women. Lacasse et al. report identical results [13]. There is no clear interpretation for this finding, however, some authors suggest that moderate amounts of alcohol reduce stress [14,15]. Although alcohol use may look beneficial, it has a lot of negative effects on pregnancy outcome, and moreover it can lead to fetal alcohol spectrum disorder [16,17]. Therefore, we would strongly advice against the use of alcohol during pregnancy. We also found several dietary factors that negatively affect MCS or PCS and are hardly explained by the current evidence in literature. For example, fruit and vegetable consumption reduces both PCS and MCS, and warm food and fish intake reduces PCS alone. We want to address our findings regarding oral supplements separately as they are widely used in pregnancy. We found that only iron supplements have positive impact on MCS, whereas the use of folic acid significantly reduces MCS. In addition to this, our findings suggest that the use of all other oral supplements have only negative effects on PCS. It is proven that iron supplements improve the well-being of women during pregnancy by preventing iron deficiency anemia, which is very prevalent in pregnant women [18].

We thought that all perianal symptoms would be associated with worse QOL, however, to our surprise we found several perianal variables that significantly increase PCS and MCS. These include straining during defecation (PCS and MCS) and fecal incontinence that requires change in lifestyle (MCS only). Johannessen et al.'s study completely contradicts this finding, as they determined that fecal incontinence during pregnancy greatly impairs quality of life in the psychological domain [19].

The number of pregnancies significantly reduces PCS; this has been reported in many times in the literature. A study by Hama et al. reports that multiparous women report better QOL during pregnancy and a study by Chang et al. report opposite results regarding parity [11,20]. Weight gain during pregnancy negatively affects only MCS. One study refers that weight gain in pregnancy can cause discomfort in general [21]. History of perineal tear during delivery has a negative impact on both MCS and PCS, this was also proven in a study by Monard et al. [22]. Perineal tear in some cases can be partly avoided by choosing episiotomy or by performing antenatal perineal massage $[23,24]$. However, the latter method is debatable [25].

Cold working environment was associated with higher QOL (both MCS and PCS). We can only speculate on the causes, but it is known that during pregnancy women experience hormonal changes, 
especially fluctuation of estrogen levels, which can lead to hot flushes, and thus lower temperatures could be more comfortable [26]. We also analyzed how physical activity affects QOL. Weekly exercises tend to increase MCS of pregnant women, however vigorous physical activity and lifting more than 10 kilograms daily reduces PCS and MCS respectively. Guidelines on physical activity during pregnancy differ throughout countries, some of them allow intensive physical activities [27], however, most of them recommend moderate daily exercises $[27,28]$. Intensive physical activity before pregnancy can become unbearable throughout pregnancy due to decline in physical functioning [29-31].

We also analyzed whether QOL during the first trimester of pregnancy is associated with newborn weight. We found that women with lower PCS and MCS scores tended to give birth to newborns who were large for their gestational age. This could be clinically relevant, as large for gestational age newborns and their mothers tend to have more complications during labor [32-34]. Current evidence in the literature is limited, but suggests that worse QOL is associated with higher oxidative stress and lower birthweight [35].

The strengths of this study are the prospective nature of our collected data and the application of a standardized QOL questionnaire SF-36. The main advantage is the analysis of a very broad spectrum of variables that can impact women's QOL, this allows us to accurately produce a predictive regression model.

One of the drawbacks of our study is the narrow period of interest (only the first trimester of pregnancy). As the pregnancy grows, women face more physiological changes, therefore analysis of the other two trimesters could be as, if not more, important in identifying other variables influencing women's QOL.

Findings from our study could be important in clinical practice as some of the variables determined can be modified. Different interventions can be developed to improve QOL of pregnant women. Interventions to improve quality of life take time to bring results, therefore actions must start as early as possible- before conception or in the early pregnancy periods [8]. The literature suggests such interventions are most effective in the earlier, periconceptional, period, as this is a key time for fetal development [7].

\section{Conclusions}

In conclusion, we found several significant variables that impact women's QOL during the first trimester of pregnancy. Some of the variables are new and their interactions can be difficult to explain, thus further investigation is needed to explore them. The modifiable risk factors we determined could be important in clinical practice for developing and promoting interventions to improve maternal QOL in the first trimester, as this is a key time for fetal development. Moreover, we acknowledge that lower QOL during first trimester is associated with newborns who are large for gestational age.

Author Contributions: L.J. and M.J. interpreted the patient data and were the major contributors in writing the manuscript. A.M. analyzed and interpreted the patient data. D.B. and G.D. major contributors in patient data collection and design of the study. D.R. major contributor in reviewing the manuscript. T.P. major contributor in patient data collection, design of the study and manuscript revision. All authors read and approved the final manuscript.

Funding: This research received no external funding

Conflicts of Interest: The authors declare no conflict of interest.

\section{References}

1. Bennett, H.A.; Einarson, A.; Taddio, A.; Koren, G.; Einarson, T.R. Prevalence of depression during pregnancy: systematic review. Obstet. Gynecol. 2004, 103, 698-709. [CrossRef] [PubMed]

2. Dunkel Schetter, C.; Tanner, L. Anxiety, depression and stress in pregnancy: Implications for mothers, children, research, and practice. Curr. Opin. Psychiatry 2012, 25, 141-148. [CrossRef] [PubMed] 
3. Glynn, L.M.; Schetter, C.D.; Hobel, C.J.; Sandman, C.A. Pattern of perceived stress and anxiety in pregnancy predicts preterm birth. Health Psychol. Off. J. Div. Health Psychol. Am. Psychol. Assoc. 2008, 27, 43-51. [CrossRef] [PubMed]

4. Mirghafourvand, M.; Mohammad-Alizadeh-Charandabi, S.; Asghari Jafarabadi, M.; Shiri, F.; Ghanbari-Homayi, S. Feasibility, Reliability, and Validity of the Iranian Version of the Quality of Life Questionnaire for Pregnancy. Iran. Red Crescent Med. J. 2016, 18. [CrossRef] [PubMed]

5. Morin, M.; Vayssiere, C.; Claris, O.; Irague, F.; Mallah, S.; Molinier, L.; Matillon, Y. Evaluation of the quality of life of pregnant women from 2005 to 2015. Eur. J. Obstet. Gynecol. Reprod. Biol. 2017, 214, 115-130. [CrossRef] [PubMed]

6. $\quad$ Lagadec, N.; Steinecker, M.; Kapassi, A.; Magnier, A.M.; Chastang, J.; Robert, S.; Gaouaou, N.; Ibanez, G. Factors influencing the quality of life of pregnant women: a systematic review. BMC Pregnancy Childbirth 2018, 18, 455. [CrossRef] [PubMed]

7. Inskip, H.M.; Crozier, S.R.; Godfrey, K.M.; Borland, S.E.; Cooper, C.; Robinson, S.M. Women's compliance with nutrition and lifestyle recommendations before pregnancy: general population cohort study. BMJ 2009, 338, b481. [CrossRef]

8. Chandranipapongse, W.; Koren, G. Preconception counseling for preventable risks. Can. Fam. Physician 2013, 59, 737-739.

9. Poskus, T.; Buzinskienè, D.; Drasutiene, G.; Samalavicius, N.; Barkus, A.; Barisauskiene, A.; Tutkuviene, J.; Sakalauskaite, I.; Drasutis, J.; Jasulaitis, A.; et al. Haemorrhoids and anal fissures during pregnancy and after childbirth: a prospective cohort study. BJOG Int. J. Obstet. Gynaecol. 2014, 121, 1666-1671. [CrossRef]

10. Jomeen, J.; Martin, C.R. The factor structure of the SF-36 in early pregnancy. J. Psychosom. Res. 2005, 59, 131-138. [CrossRef]

11. Chang, S.-R.; Chen, K.-H.; Lin, M.-I.; Lin, H.-H.; Huang, L.-H.; Lin, W.-A. A repeated measures study of changes in health-related quality of life during pregnancy and the relationship with obstetric factors. J. Adv. Nurs. 2014, 70, 2245-2256. [CrossRef] [PubMed]

12. Greden, J.F. Anxiety or caffeinism: a diagnostic dilemma. Am. J. Psychiatry 1974, 131, 1089-1092. [PubMed]

13. Lacasse, A.; Rey, E.; Ferreira, E.; Morin, C.; Bérard, A. Nausea and vomiting of pregnancy: what about quality of life? BJOG Int. J. Obstet. Gynaecol. 2008, 115, 1484-1493. [CrossRef] [PubMed]

14. Watt, M.H.; Eaton, L.A.; Choi, K.W.; Velloza, J.; Kalichman, S.C.; Skinner, D.; Sikkema, K.J. “It's better for me to drink, at least the stress is going away": perspectives on alcohol use during pregnancy among South African women attending drinking establishments. Soc. Sci. Med. 1982 2014, 116, 119-125. [CrossRef] [PubMed]

15. Baum-Baicker, C. The psychological benefits of moderate alcohol consumption: A review of the literature. Drug Alcohol Depend. 1985, 15, 305-322. [CrossRef]

16. Patra, J.; Bakker, R.; Irving, H.; Jaddoe, V.W.V.; Malini, S.; Rehm, J. Dose-response relationship between alcohol consumption before and during pregnancy and the risks of low birthweight, preterm birth and small for gestational age (SGA)-a systematic review and meta-analyses. BJOG Int. J. Obstet. Gynaecol. 2011, 118, 1411-1421. [CrossRef] [PubMed]

17. Pruett, D.; Waterman, E.H.; Caughey, A.B. Fetal alcohol exposure: consequences, diagnosis, and treatment. Obstet. Gynecol. Surv. 2013, 68, 62-69. [CrossRef]

18. Makrides, M.; Crowther, C.A.; Gibson, R.A.; Gibson, R.S.; Skeaff, C.M. Efficacy and tolerability of low-dose iron supplements during pregnancy: a randomized controlled trial. Am. J. Clin. Nutr. 2003, 78, 145-153. [CrossRef]

19. Johannessen, H.; Mørkved, S.; Stordahl, A.; Sandvik, L.; Wibe, A. Anal incontinence and Quality of Life in late pregnancy: a cross-sectional study. BJOG Int. J. Obstet. Gynaecol. 2014, 121, 978-987. [CrossRef]

20. Hama, K.; Takamura, N.; Honda, S.; Abe, Y.; Yagura, C.; Miyamura, T.; Obama, M.; Morisaki, M.; Imamura, S.; Aoyagi, K. Evaluation of Quality of Life in Japanese Normal Pregnant Women. Acta Med. Nagasakiensa 2007, 52, 95-99.

21. Rodriguez, A.; Bohlin, G.; Lindmark, G. Symptoms across pregnancy in relation to psychosocial and biomedical factors. Acta Obstet. Gynecol. Scand. 2001, 80, 213-223. [CrossRef] [PubMed]

22. Monard, B.; Sagon, M.-J.; Chehab, M.; Riethmuller, D.; Ramanah, R. Post-partum quality of life after second degree perineal tears. Eur. J. Obstet. Gynecol. Reprod. Biol. 2016, 206, e78-e79. [CrossRef] 
23. Handa, V.L.; Blomquist, J.L.; McDermott, K.C.; Friedman, S.; Muñoz, A. Pelvic Floor Disorders After Childbirth: Effect of Episiotomy, Perineal Laceration, and Operative Birth. Obstet. Gynecol. 2012, 119, 233-239. [CrossRef] [PubMed]

24. Beckmann, M.M.; Stock, O.M. Antenatal perineal massage for reducing perineal trauma. Cochrane Database Syst. Rev. 2013, CD005123. [CrossRef] [PubMed]

25. Stamp, G.; Kruzins, G.; Crowther, C. Perineal massage in labour and prevention of perineal trauma: randomised controlled trial. BMJ 2001, 322, 1277-1280. [CrossRef] [PubMed]

26. Hanisch, L.J.; Bennett, I.M.; Freeman, E.W.; Coyne, J.C. Hot flashes during pregnancy: a comparative study. Eur. J. Obstet. Gynecol. Reprod. Biol. 2010, 151, 38-40. [CrossRef] [PubMed]

27. Evenson, K.R.; Barakat, R.; Brown, W.J.; Dargent-Molina, P.; Haruna, M.; Mikkelsen, E.M.; Mottola, M.F.; Owe, K.M.; Rousham, E.K.; Yeo, S. Guidelines for Physical Activity during Pregnancy: Comparisons From Around the World. Am. J. Lifestyle Med. 2014, 8, 102-121. [CrossRef] [PubMed]

28. ACOG Committee. Opinion, No. 650: Physical Activity and Exercise During Pregnancy and the Postpartum Period. - PubMed - NCBI. Available online: https://www.ncbi.nlm.nih.gov/pubmed/26595585 (accessed on 8 June 2019).

29. Haas, J.S.; Jackson, R.A.; Fuentes-Afflick, E.; Stewart, A.L.; Dean, M.L.; Brawarsky, P.; Escobar, G.J. Changes in the health status of women during and after pregnancy. J. Gen. Intern. Med. 2005, 20, 45-51. [CrossRef]

30. Hueston, W.J.; Kasik-Miller, S. Changes in functional health status during normal pregnancy. J. Fam. Pract. 1998, 47, 209-212. [PubMed]

31. Förger, F.; Østensen, M.; Schumacher, A.; Villiger, P.M. Impact of pregnancy on health related quality of life evaluated prospectively in pregnant women with rheumatic diseases by the SF-36 health survey. Ann. Rheum. Dis. 2005, 64, 1494-1499. [CrossRef]

32. Boulet, S.L.; Alexander, G.R.; Salihu, H.M.; Pass, M. Macrosomic births in the united states: determinants, outcomes, and proposed grades of risk. Am. J. Obstet. Gynecol. 2003, 188, 1372-1378. [CrossRef] [PubMed]

33. Raio, L.; Ghezzi, F.; Di Naro, E.; Buttarelli, M.; Franchi, M.; Dürig, P.; Brühwiler, H. Perinatal outcome of fetuses with a birth weight greater than $4500 \mathrm{~g}$ : an analysis of 3356 cases. Eur. J. Obstet. Gynecol. Reprod. Biol. 2003, 109, 160-165. [CrossRef]

34. Friedlander, Y.; Paltiel, O.; Manor, O.; Deutsch, L.; Yanetz, R.; Calderon, R.; Siscovick, D.S.; Harlap, S. Birthweight of Offspring and Mortality of Parents: The Jerusalem Perinatal Study Cohort. Ann. Epidemiol. 2007, 17, 914-922. [CrossRef] [PubMed]

35. Shastri, L.; Pammal, R.S.; Mani, I.; Thomas, T.; Kurpad, A.V. Oxidative stress during early pregnancy and birth outcomes. Public Health Nutr. 2016, 19, 3210-3215. [CrossRef] [PubMed] 